\title{
A CAPITAL NO PLANALTO DE GOYAZ
}

$O$ recente decreto que manifesta a resolução do Governo de fazer a apegação ou tomada de posse do terreno necessario para a mudança da capital de nossa patria para o interior do paiz, determinou-me a escrever o presente artigo. Estou de accôrdo em que se faça a mudança, mas não para o remoto sertão indicado no art. 3. da Constituição Federal. Desde que o nosso Presidente, o eminente constitucionalista Dr. Epitacio, se deolarou revisionista, sustentando a necessidade premente de se instituir o veto parcial, nenhum motivo ha para que eu não trabalhe para a modificação do art. $3 .^{\circ}$, que me pareceu ter sido escripto imponderadamente, num momento de agitação, qual o que se segue ás transformações sociaes. Demais, em vista do art. 34 n. 13 da Constituição Federal, entendo que a materia é da competencia do Congresso Legislativo ordinario, e não da alçada exclusiva de uma Constituinte. Foi essa mania de reformas radicaes que, pouco depois do advento da republica, inspirou a diversos patriotas a idéa de pagar a divida nacional por meio de uma subscripção popular, idéa que arrefeceu, não tanto pela demonstração que fizeram os economistas da impossibilidade da execução do plano, quanto pelo fausto ostentado pelo Sr. Quintino Bocayuva, quando foi ao Prata entender-se com os argentinos sobre o territorio das Missões.

Os inconvenientes da capital maritima foram reconhecidos em todos os tempos. Ao estudarem os sociologos a lei denominada das altitudes, recordam que os antigos consideravam as cidades situadas na proximidade do mar, como sendo sujeitas aos improvisos, aos ataques inespera. 
dos e á corrupção dos costumes. Foi por se haverem persuadido de que era recurso de defesa contra os inimigos, e meio de conservação da pureza moral, que os povos primitivos collocaram as cidades nas alturas, e longe do mar, e só, á medida que a segurança cresceu com o progresso, e com a cessação da desconfiança mutua, desceram ellas para as planicies, e passaram do interior para a beira-mar: é a lei das altitudes. Strabão, Thucydides, Platão, Aristoteles e Cicero, dentre muitos, condemnaram as cidades maritimas pelos motivos estrategicos e moraes que acabo de indicar.

Mas dahi não se conclue que se deve mudar a capital para um ponto de difficil accesso, mesmo para os do paiz. A isto se oppõem considerações de ordem economica e principios sociologicos. Platão queria, sim, que a cidade fosse interior, e não maritima, mas julgava bastante que fosse levantada a 80 stadios do mar. Um stadio equivalia a $1 / 8$ de milha, ou a 184 metros. A terrifica preoccupação pois de um ataque maritimo parecia ao philosopho grego desfeita com o afastamento da capital cerca de 150 kilometros para o interior do paiz.

Lembrarei que Washington está a 188 kilometros da bahia de Cheapside. Não houve, creio, quem se lembrasse de levar a capital para o Far West: o desconforto do logar seria motivo sufficiente para desaconselhar esse proposito, mas ha outras razóes, que militam contra afastarse dos centros povoados a capital.

Permitta-me o leitor uma digressão pelo terreno das industrias, para mostrar o que será despendido continuamente, a todo momento, quando houvermos, o que nunca succederá, segundo creio, levado a effeito a mudança da Capital para o agro sertão de Goyaz.

A par da divisão do trabalho nas manufacturas, têm os economistas mostrado que se deve attender ao es- 
forço de tracção, ao peso morto, á resistencia opposta pelo mau caminho nos transportes; ás idas e vindas de mercadorias, á passagem do dinheiro de um lugar para outro, o que se obvia não só pela letra de cambio, mas tambem pelơ cheque e pelas camaras, de compensação.

Dahi essa lei que De Greef formula nos seguintes termos: "O progresso opera-se no sentido da reducção do peso morto, do esforço de tracção, das dẻspezas de circulação, do lucro, do uso" Além de todas essas difficuldades que surgem no transporte de mercadorias de toda especie, deve considerar-se o ir e vir do operario, que é um factor de despeza passado despercebido aos mais sagazes espiritos, aos mais agudos industriaes, até que Taylor mostrou ser a producção grandemente encarecida por esse facto, de onde a taylorização, que consiste em reduzir ao minimo as idas e vindas dos operarios nas officinas. Ora tudo isto é muito claro, mas muito parecido com o ovo de Colombo. Ninguem era capaz de prever o resultado assombroso que deram a divisão do trabalho, o facilitar-se a circulação e a taylorização nas industrias. Tambem direi que a poucos espiritos de politicos occorrerá quanto vai custar de transportes e de idas e vindas, e quanto tempo, posta a Capital em Goyaz, fará ella perder-se. Imagine-se: a correspondencia postal, os generos de que necessitam homens civilizados, a passagem constante de deputados, senadores, altos funccionarios, e de suas familias Tenha-se presente que essa gente ha de vir a São Paulo, ou ha de ir ao Rio, para mil necessidades que a civilização criou. Considere-se que quasi todos fazem estações bolnearias, que hão de ouvir clinicos e especialistas, que hão de querer ter livros, que não se enencontram no sertão, oculos com vidros convenientes, mil objectos a que estão habituados, ficar em dia com as novidades scientificas, litterarias, artisticas Uma insignificancia, dir-me-hão. Era o que se pensava antes de ap- 
plicadas a divisão do trabalho a taylorização e a reducção das difficuldades de transporte ao minimo; era o que se pensava antes da criação da letra, do cheque, das camaras da compensação; era o que se pensava antes que as estatisticas houvessem provado quanto esses melhoramentos tinham beneficiado a humanidade, levando o conforto as lar do pobre.

Mas admitta-se que seja uma nuga o que se vai gastar em vai vem. Ha ainda a difficuldade de ter solução a qualquer negocio. Considere-se que o planalto não é sinão o céntro material do Brasil, tomado o nosso paiz, como sendo um territorio. $O$ centro da actividade, o centro da parte viva do paiz é justamente aquella porção, aquella zona onde a intensidade da população se accentuou, devendo-se observar que o territorio até hoje occupado é uma nesga de terra na costa, achando-se o interior ainda muito pouco explorado, e devendo assim ficar provavelmente por muitas dezenas de annos, ou quiçá por muitos seculos. Em 1889, não se esperava que tanto se retardasse o povoamento do solo, illudidos os constituintes pela entrada de milhares de immigrantes que se amaravam na Europa em busca de nossa patria. Não se afigurava aos constituintes o planalto como sendo uma região longinqua, de dispendiosissimo accesso, falta dos confortos a que estão habituados os homens civilizados, o escol da nação. Foi por este motivo que entenderam dever ser elle estabelecido como o centro do convivio social em nossa patria.

Ultimamente fallou-se da fertilidade do planalto, da doçura do clima, da abundancia das aguas e de sua excellencia, e, com essas considerações, pretenderam muitos jornalistas esteiar a idéa da mudança da Capital para a longinqua paragem escolhida na época das abnegações, dos desapegos, das renuncias aos prazeres, dos sacrificios patrioticos. Si os altos funccionarios que para lá de- 
verão transportar seus penates fossem alimentar-se de tutu de feijão com torresmo, arroz com suan, lombo de porco, cambuquira, quibêbe de abobora, quimgobô, cangica, melaço com cará; café com mandioca assada ou com pipocas; si bebessem jacuba, garapa, aluá e maduro, barato viveriam; mas não: irão do mar os camarões, a garoupa, a pescada, o roballo, a lagosta e as ostras; dos grandes rios, a piracajuba e o dourado; dos centros de cultura, os espargos, as alcaxofras, os sersifins e os crosnes; dentre as conservas, os cogumelos, o foie gras, o caviar e as tubaras; e das bebidas, os vinhos de Bordeos e de Borgonha e o capitoso champanha Muitas dessas victualhas irão em gelo, e deverão ser quiçá estabelecidos vagões frigorificos. Mas quem paga tudo isto? O povo, do qual fazemos parte o leitor e eu. Tremei algibeiras dos contribuintes!

Mas deixarei o aspecto patrimonial, o elevado preço de tudo quanto é indispensavel á vida das pessoas de certo trato (e ensinação já deveriamos ter tido com o que observamos no Acre), e vou occupar-me com a feição moral do projecto. Affirmou-se que, nas grandes cidades, campeia a corrupção dos costumes, e que são pois ellas improprias para capitaes. $\mathrm{O}$ argumento tem duas modalidades. Nos tempos primitivos, quando os povos nutriam a convicção de que cada um delles estava com a verdade, com a boa moral, com os melhores costumes, com as mais perfeitas leis, zelosamente cuidavam de não receberem o que os modernos denominam a civilização dativa. Era uma fórma da xenophobia. Eis como falla Cicero, ainda imbuido neste preconceito, e para quem só os gregos e romanos eram povos civilizados, devendo-se haver como barbaros todos os outros: "As cidades maritimas devem temer a alteração e a corrupção dos costumes. Nellas se misturam as linguas e os costumes de toda a Terra; os ex. trangeiros para ellas trazem seus costumes com as suas 
mercadorias; correndo os tempos, todas as instituições nacionaes são atacadas, nenhuma escapa." Modernamente toma outra forma o argumento: diz-se que, nas grandes cidades, é mais facil assediar os politicos. Referindo-se ha dias a essa accessibilidade, escreveu o Presidente da Republica: "O Legislativo, o MAIS ACCESSIVEL ás influencias extranhas, e onde a divisão da responsabilidade enfraquece as resistencias geraes e os excessivos rigores ou autoriza condescendencias demasiadas. " ("Jornal do Commercio", ed. de S. Paulo, numero de 11 de março). Despedaçou-me o coração a leitura dessas palavras de quem deve conhecer os nossos homens publicos. A locução MAIS ACCESSIVEL traz ao espirito que os cidadãos, noutros poderes, tambem são ACCESSIVEIS. Triste, muito triste !!!!! A phrase do eminente politico corresponde á melancolica, desataviada e mesmo chula do negociante que dizia "estar a zona estragada". Não é pois só a zona mercantil que se achava avariada: tambem a politica !!! Mas o remedio não está na mudança da capital. Para mim tão corrupta é a gente do interior do paiz, quanto a das cidades populosas. Sei de caboclo affeito a beber agua no gommo do taquaraçú, que $\mathrm{fez}$ a propria mulher procurar amores com um vizinho, afim de surripiar deste um documento. Não se fez peior entre gente que toma champanha em taças de crystal. Mas, quando fosse o interior mais propicio meio para a cultura dos altos preceitos da Moral, não é menos verdade que os corruptores lançariam mão todos os meios para alcançarem approximar-se dos politicos que tencionassem seduzir. Haverá homem tấo ingenuo que supponha que os empreiteiros de negociatas possam encontrar difficuldades em destacar do Rio de Janeiro um socio para o planalto, afim de assediar, este os politicos, e conseguir que a associação salteie o erario publico? 
Como tudo é argumento quando se quer defender uma idéa por menos razoavel que ella seja, chegou-se a dizer que a Capital no interior seria um centro de irradiação de cultura, um faetor do progresso local, e que este se expandiria pelas regióes adjacentes. Esqueceram-se esses taes de que á acção do homem sobre o meio que o circumda se oppõe a reacção do meio. Eu explicarei com factos essa lei sociologica, uma das mais conhecidas, e mais frequentemente citadas, por ser das basicas. Conta Southey que alguns poucos inglezes, victimas de um naufragio á foz do rio Parahyba do Sul, foram annos após o desastre, encontrados em perfeito estado de selvageria, confundidos com os indigenas. Sabem todos os paulistas que a colonia allemã de Santo Amaro, proximo a esta Capital, de tal modo soffreu a influencia do meio, que hoje é difficil distinguir um filho allemão nascido na circumvinzinhanças desta Capital de um genuino caboclo brasileiro, um descendente dos onossos primitivos bugres. Muita gente deve saber que ha bons 30 ou 40 annos, um dos nossos respeitaveis politicos trouxe de Goyaz um bugrinho, que muito se lhe affeiçoára. Anda o indigena pelas nossas ruas, e difficil será distinguil-o dos outros mestiços, dos creoulos. Si se désse o facto contrario, si houvesse um branco paulista ficado 30 annos no meio dos indios, hoje se acharia nas condições dos inglezes encontrados á margem do rio Parahyba. Ora, eu não quero dizer que os nossos altos funccionarios se tornem selvagens no planalto, mas força será a todos confessar que hão de soffrer, por mais que reajam contra a influencia do meio, a acção deste. Já me vou tornando enfandonho. Devo pôr termo a estas minhas ponderações. Sou pela mudança da capital. Ainda ha pouco, Bryce fez-nos sentir a necessidade desta medida por occasião da revolta de João Candido. 
Creio porém, que, transposta a Serra do Mar, na Barra do Pirahy, no alto da Serra de Santos, já está o nosso Governo assás acautelado contra as investidas dos inimigos que possam atacar-nos por mar. Procure-se um logar á margem da Central, da Mogyana ou da Paulista que tenha elementos para nelle se estabelecer uma grande cidade, e ahi está o ponto em que deverá ser collocada a capital da União, sem os enormes encargos economicos que a situada no planalto nos acarretará. Não seria ainda mais facil, mais pratico, collocar a Capital em Petropolis?

João Arruda. 